\title{
Morfoanatomia das folhas de Dodonaea viscosa Jacq., Sapindaceae
}

\author{
Melânia P. Manfron, "Lisiane Bajerski, Marcelo D. Malesuik, Gilberto D. Zanetti \\ Universidade Federal de Santa Maria, Centro de Ciências da Saúde, Departamento de Farmácia Industrial. \\ Av. Roraima, Prédio 26, $97105-900$ Porto Alegre-RS, Brasil.
}

\begin{abstract}
RESUMO: Dodonaea viscosa Jacq., Sapindaceae, é uma planta tradicionalmente utilizada como antifebril, anti-reumática e antimicrobiana. Neste trabalho foram determinados parâmetros morfoanatômicos, por análise macro e microscópicas, das folhas de Dodonaea viscosa, com o objetivo de auxiliar sua diagnose como insumo farmacêutico. Macroscopicamente as folhas apresentam limbo com forma lanceolada, margem inteira, consistência áspera e venação eucamptódroma. O pecíolo é curto, reto e em seção transversal é triangular com os ângulos arredondados. Microscopicamente destaca-se a cutícula com formações lenticulares, os tricomas glandulares com quatro células na base, os tricomas tectores unicelulares de ápice afilado, os estômatos higrofíticos dispostos apenas na face abaxial da epiderme, o parênquima paliçádico com até três camadas de células e os feixes vasculares com xilema envolto por floema e cordões de parênquima que ligam um maciço central de células de parênquima a uma bainha de esclerênquima. Estas características morfo-anatômicas, quando analisadas em conjunto, contribuem no controle botânico de qualidade das folhas de Dodonaea viscosa como insumo farmacêutico.
\end{abstract}

Unitermos: Morfo-anatomia, farmacobotânica, Dodonaea viscosa, Sapindaceae, plantas medicinais.

\begin{abstract}
Morph-anatomy of the leaves of Dodonaea viscosa Jacq., Sapindaceae". Dodonaea viscosa Jacq., Sapindaceae, is a plant traditionally used as anti fever, anti- rheumatic and antimicrobial. This work determined morpho-anatomical parameters, by macro and microscopic analysis of Dodonaea viscosa leaves, aiming to reach their diagnosis as pharmaceutical input. Macroscopically, the leaves have a lanceolate shape limb, full margin, rough consistence and venation eucamptodromous. The petiole is short, straight and in transversal section it is triangular with round angles. Microscopically, the lenticullar formation cuticle is seen with prominence, the glandular thricomes are seen with four cells on the base, the non-glandular unicellular thricomes are seen with pointed apex, the higrophitic stomatas are disposed in the lower surface epidermis only, the palisade parenchyma show up to three-cell layers and vascular bundles with xylem involved by phloem and parenchyma lines which bound a central mass of parenchyma cells to a sclerenchyma sheath. This morph-anatomical characteristic, when analyzed in group, contributes to the botanical quality control of Dodonaea viscosa leaves as pharmaceutical input.
\end{abstract}

Keywords: morpho-anatomy, pharmacobotanic, Dodonaea viscosa, Sapindaceae, medicinal plants.

\section{INTRODUÇÃO}

A família Sapindaceae compreende cerca de mil e seissentas espécies vegetais agrupadas em cento e quarenta gêneros (Souza \& Loirenzi, 2005). As plantas pertencentes à família Sapindaceae encontram-se distribuídas geralmente em regiões tropicais e sub-tropicais, sendo que poucas espécies chegam às regiões extratropicais. Morfologicamente caracterizando-se por apresentarem pétalas com apêndices glandulosos ou escamosos, disco assimétrico extra-estaminal, ovário tricarpelar, semente geralmente dotada de arilo e fruto comumente alado (Souza \& Loirenzi, 2005; Schultz, 1985).
Dodonaea viscosa Jack., planta conhecida popularmente por vassoura-vermelha, é um arbusto ou árvore de copa rala que atinge quatro a oito metros de altura, com folhas simples ealternas, flores tetrâmeras e andrógenas e frutos do tipo cápsula-samaroide que comportam três a quatro alas (Lorenzi \& Matos, 2002; Schultz, 1985; Reitz, 1972). Esta espécie ocorre em todas as formações tropicais do mundo, e no Brasil ocorre principalmente junto à orla litorânea, em formações de restingas e planícies, e em encostas de serras (Sobral \& Jarenkow, 2006; Lorenzi \& Matos, 2002; Hew, 2001). As folhas desta planta são amplamente utilizadas em medicina tradicional, na forma de chás, devido à ação antifebril, e na forma de cataplasmas, 
nos casos de reumatismo, gota e cólicas intestinais, como também são utilizadas para combater doenças venéreas (Lorenzi \& Matos, 2002; Simões, 1995; Reitz, 1972). As folhas de Dodonaea viscosa apresentam flavonoides, saponinas diterpenos e do ácido dodônico (Wagner et al., 1987; Ahmad et al., 1987; Sachdev \& Kulshreshtha, 1983). Almeida et al. (2001) destaca ainda a presença de mucilagens, cumarinas, cardiotônicos e óleos voláteis. Rojas (1992) determinou no extrato metanólico das folhas de Dodonaea viscosa atividade antimicrobiana em ensaios com Candida albicans e bactérias Gram positivas e Gram negativas. Almeida et al. (2001), determinaram baixa toxicidade aguda, via intraperitonial em camundongos, e efeito inibitório significativo em inflamação aguda em ratos no extrato hidroetanólico das folhas de Dodonaea viscosa.

O presente trabalho tem como objetivo determinar características macro e microscópicas das folhas de Dodonaea viscosa no estado íntegro e pulverizado, com a finalidade de contribuir no controle de qualidade botânica desta planta como insumo farmacêutico.

\section{MATERIAL E MÉTODOS}

Folhas de Dodonaea viscosa Jacq., Sapindaceae, foram coletadas na cidade de Santa Maria-RS, e uma amostra do material vegetal foi identificado e depositado no Herbário do Departamento de Farmácia Industrial da Universidade Federal de Santa Maria, conforme exsicata HDFI 128.

A análise morfológica foi efetuada através de estereomicroscópio (aumento $10 \mathrm{x}$ ) e a folha foi diafanizada para a análise da venação, conforme Strimatter (1973) e Hickey (1974).

A análise anatômica foi realizada em seções paradérmicas em lâminas temporárias, com material fresco, seccionadas a mão livre e coradas com azul de metileno a 0,05\% (Oliveira \& Akisue, 1989). Para a obtenção de seções transversais porções de 2 × $2 \mathrm{~mm}$ da região mediana-distal de folhas adultas e frescas foram fixadas em glutaraldeído $2 \%$ em PBS, passando por desidratação em série etílica ascendente e processado para microscopia óptica com inclusão em blocos de hidroxietilmetacrilato (Gerrits \& Smidt, 1983; Ruetze \& Schimitt, 1986). Seções de $4 \mu \mathrm{m}$ foram obtidas em micrótomo rotativo, repassadas para lâminas e coradas com azul de toluidina 0,05\% (Gerlach, 1977). O material foi observado em microscópio de campo claro e as seções foram analisadas tomando por base Appezzato-da-Glória \& Carmello-Guerreiro (2003), Dickison (2000), Esaú (1990), Fahn (1990) e Cutter (1987) e microfotografado em microscópio com câmara digital. As lâminas foram depositadas no laminário do Departamento de Farmácia Industrial, Universidade Federal de Santa Maria.

\section{RESULTADOS E DISCUSSÃO}

\section{Análise macroscópica}

Através da análise macroscópica observou-se que as folhas de Dodonaea viscosa Jacq., Sapindaceae, assumem disposição alterna, são discolores, pouco luzidias e curto-pecioladas. O limbo apresenta forma lanceolada, atinge em média $7 \mathrm{~cm}$ de comprimento e $3 \mathrm{~cm}$ de largura, possui ápice acuminado, base atenuada, margem inteira e consistência áspera (Figura 1 A-B), apresentando em toda a superfície pontuações translúcidas. A venação é caracteristicamente pinada, do tipo eucamptódroma, com aréolas de forma variada, nervuras menores do tipo simples ou ramificadas e terminações de nervura com apenas xilema envolto por parênquima. O pecíolo é reto, atinge 5-10 mm de comprimento, e em seção transversal apresenta forma triangular com os ângulos arredondados.

Os caracteres morfológicos observados, nas folhas de $D$. viscosa, são coincidentes aos descritos para a família Sapindaceae (Souza \& Lorenzi, 2005; Cronquist, 1981; Barroso, 1991; Joly, 1998), sendo as folhas simples em Sapindaceae características apenas para o gênero Dodonaea (Souza \& Lorenzi, 2005). As características morfológicas destacadas neste trabalho também são concordantes as encontradas na literatura para a espécie em questão, podendo ser ressaltado a presença de folhas simples, a ausência de estípulas, a consistência cartácea, o aspecto viscoso e a filotaxia alterna (Lorenzi \& Matos, 2002; Lorenzi, 1998).

\section{Análise microscópica}

Em D. viscosa a face adaxial da lâmina foliar em vista superior (Figura 2A) apresenta células epidérmicas de parede celular reta, ausência de estômatos. Também ocorre esparsos tricomas tectores localizados próximos a nervura central e tricomas glandulares distribuídos por toda a extensão do limbo. Na face abaxial (Figura 2B) a lâmina foliar apresenta células epidérmicas com parede celular reta, estômatos do tipo anomocítico e esparsos tricomas glandulares, similares aos observados na face adaxial.

Em seção transversal fica evidente a presença de uma epiderme constituída de apenas uma única camada de células, sendo que na face adaxial as células epidérmicas exibem, em geral, parede periclinal maior que a anticlinal. Contudo, as paredes periclinais e anticlinais das células epidérmicas podem apresentar tamanhos semelhantes e, próximo a região central e distal do limbo, estas células assumem a forma mais circular (Figura 3A). Nas duas faces (adaxial e abaxial) as células epidérmicas apresentam tamanhos semelhantes (Figura 3A e 5A). Na epiderme foliar tem-se a presença marcante de células de mucilagem, uma característica a ser destacada para D. viscosa, pois, conforme O'Brien \& McCully (1981), 
o azul de toluidina cora de púrpura (lilás) as substâncias pécticas que constituem as mucilagens, característica que pôde ser observada com certa freqüência nas seções transversais analisadas, uma vez que as seções analisadas foram tratadas com este corante. A cutícula que recobre as paredes periclinais é mais espessa na região que corresponde à nervura central e nervuras secundárias, apresentando nestas regiões, formações lenticulares (3 B-C). Os estômatos estão presentes na face abaxial e em seção transversal mostram-se salientes em relação às células epidérmicas, caracterizando o tipo higrofítico (Figura 3A e 5C). Os tricomas tectores são unicelulares e apresentam ápice afilado e cutícula verrucosa (Figura 2C). Os tricomas glandulares são pluricelulares e possuem um pedicelo constituído por quatro células (Figura 2 D-E).

As características anatômicas da cutícula, das células epidérmicas, dos estômatos e dos tricomas observados na lâmina foliar de $D$. viscosa encerram aspectos relevantes da anatomia topográfica de forma que, ao serem analisados em conjunto, contribuem na autenticidade deste órgão como insumo farmacêutico. Tanto a cutícula como a ornamentação cuticular, conforme Dickison (2000), Oliveira et al. (1993) e Cutter (1987) são marcadores anatômicos utilizados na diferença entre espécies vegetais revelando-se como importantes caracteres taxonômicos. Por outro lado, a presença de paredes celulares retas é uma característica marcante em $D$. viscosa, podendo ser útil como um critério taxonômico, principalmente quando a droga está na forma de pó. Em geral, a conformação das paredes anticlinais das células epidérmicas, em vista frontal, é utilizada como critério taxonômico por diversos autores (Wang et al., 2001). Outra característica relevante como critério taxonômico, e consequentemente útil na autenticidade de drogas, é a presença e a localização de estômatos. Em $D$. viscosa os estômatos estão apenas na face abaxial, característica que pode ser considerada como indício de uma taxa fotossintética reduzida, pois Parkhust (1978) descreve que o contrário, ou seja, a presença de estômatos nas duas faces da epiderme foliar deve representar uma vantagem na adaptação de plantas com alta capacidade fotossintética e que vivem sob luz intensa, uma vez que essa característica aumenta a condutância para a difusão de $\mathrm{CO}_{2}$.

Uma característica microscópica marcante em $D$. viscosa constitui-se na presença de tricomas glandulares e tectores. A presença ou ausência de tricomas pode ser útil no controle de qualidade de drogas vegetais. Neste sentido Oliveira et al. (1993), destacam que os tricomas são características importantes na diagnose da droga vegetal, principalmente quando a droga se apresenta fragmentada ou mesmo pulverizada. Em geral os tricomas são discutidos como anexos epidérmicos capazes de reduzirem a transpiração ao produzirem uma camada de ar parado que retém vapor (Fahn, 1986; Ricklefs, 1993), além do que, conforme Holmes \& Keiller (2002) e Hallahan et al. (2000) as folhas pubescentes tendem a ser mais efetivas na reflexão da radiação solar. Por outro lado, essas estruturas epidérmicas, conforme Hallahan et al. (2000) e Gurevitch et al. (2002) também estão associadas ao papel de defesa das plantas à ação de herbívoros e fitopatógenos, pois acabam por dificultar o sucesso de processos como os de pouso e oviposição.

Sajo \& Rudall (2002) e Bekker \& Gerritsen (1992) ressaltam que células mucilaginosas podem ter valor taxonômico, uma vez que, a localização histológica de compostos mucilaginosos é constante dentre os diferentes grupos taxonômicos (Costa, 1982), característica que se torna importante na identificação de inúmeras espécies vegetais e, consequentemente, na autenticidade de um determinado material botânico.

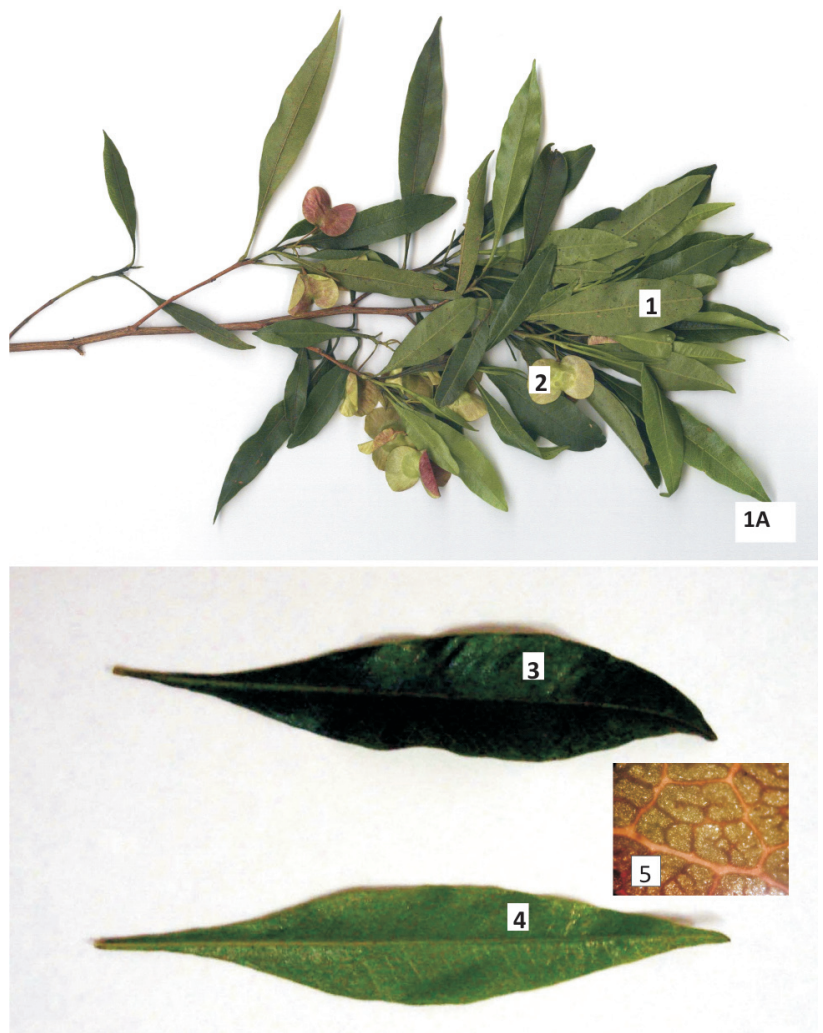

$1 B$

Figura 1A. Aspecto geral de um ramo com frutos e folhas de Dodonaea viscosa Jacq. B. Aspecto geral das folhas de Dodonaea viscosa Jacq. Legenda: 1. folhas; 2. frutos; 3. face adaxial da folha; 4. face abaxial da folha; 5. Detalhe da venação. Escala: $1 \mathrm{~cm}$.

O mesofilo é heterogêneo e assume uma posição dorsiventral (Figura 3A e 5A-C). O parênquima paliçádico está constituído por uma a três camadas de células, sendo que a primeira camada exibe células de maior comprimento (Figura 5A). O parênquima esponjoso possui quatro a seis camadas de células de forma ovóide (Figura 5 A-C). O espaço intercelular no parênquima esponjoso é do tipo câmara (Figura 5 A-C). O mesofilo dorsiventral com apenas uma camada de células paliçádicas é característico 
de ambiente úmido e sombreado (Cutter, 1987; Vieira et al., 1992). Assim é que um aumento no número de extratos do parênquima paliçádico, como o que ocorre em $D$. viscosa, pode ser visto como uma adaptação para as plantas que ocupam ambientes com características mais xéricas.

$\mathrm{Na}$ região da nervura central a lâmina foliar exibe contorno côncavo na face adaxial e convexo na face abaxial (Figura 3A). O sistema vascular é do tipo colateral e encontra-se envolto por uma bainha esclerenquimática (Figura 4A-C). O feixe vascular exibe um maciço central de células parenquimáticas, de forma arredondada, e cordões de células parenquimáticas que unem este maciço à bainha de esclerênquima constituída de três a cinco camadas de fibras (Figura 4B-C). Toda estrutura do feixe vascular é envolta por parênquima esponjoso formado por células de forma esférica e com espaço intercelular do tipo meato (Figura 3A). Subjacente à epiderme da face adaxial ocorre uma formação de colênquima anular (Figura
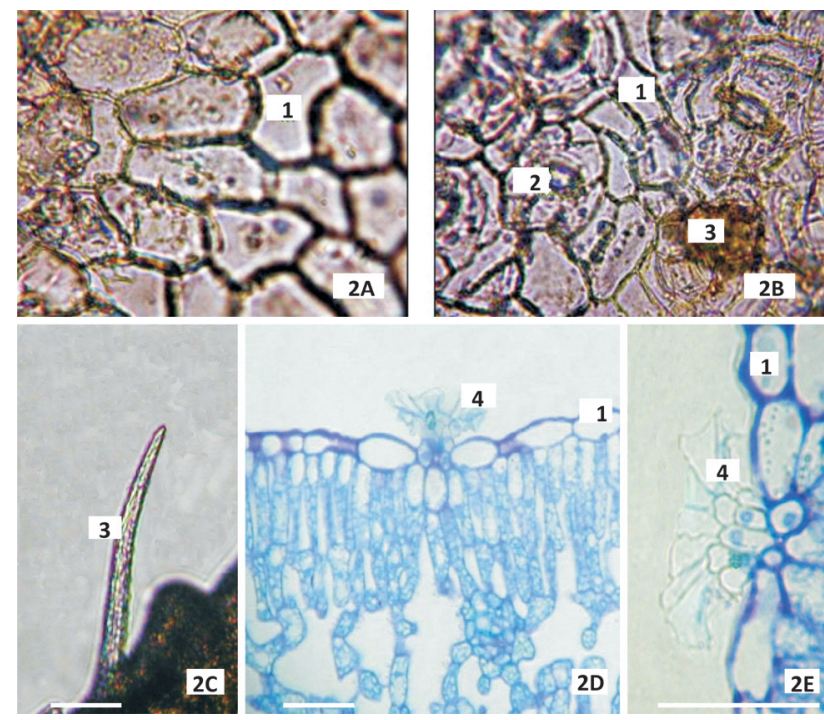

Figura 2A. Seção paradérmica da face adaxial da lâmina foliar de Dodonaea viscosa Jacq. B. Seção paradérmica da face abaxial das folhas de Dodonaea viscosa Jacq. C. Seção paredérmica da face adaxial da lâmina foliar de Dodonaea viscosa Jacq. D. Seção transversal evidenciando a face adaxial da lâmina foliar de Dodonaea viscosa Jacq. E. Seção transversal evidenciando a face abaxial da lâmina foliar de Dodonaea viscosa Jacq. Legenda: 1. células epidérmicas; 2 . estômatos; 3 . tricoma tector; 4. tricoma glandular. Escala: $20 \mu \mathrm{m}$.
3B-C), composto em média de oito camadas de células e, em íntimo contato com a face abaxial da epiderme, ocorre colênquima lacunar, constituído em média por seis camadas de células (Figura 3A).

Os feixes vasculares de segunda ordem também são do tipo colateral e estão protegidos por uma bainha de parênquima com extensões que ligam às duas faces epidérmicas (Figura 5A). Nestes feixes vasculares ocorrem células lignificadas circundantes ao floema. Os feixes vasculares de menor ordem seguem o padrão colateral e encontram-se protegidos por uma bainha parenquimática irregular que não apresenta extensões ligando às duas faces epidérmicas (Figura 4B-C). Esta característica anatômica, da planta apresentar lâmina foliar com extensão de bainha em direção à face epidérmica adaxial, conforme Karabourniotis et al. (2000), favorece a transmissão de radiação fotossintética às áreas adjacentes do mesofilo.
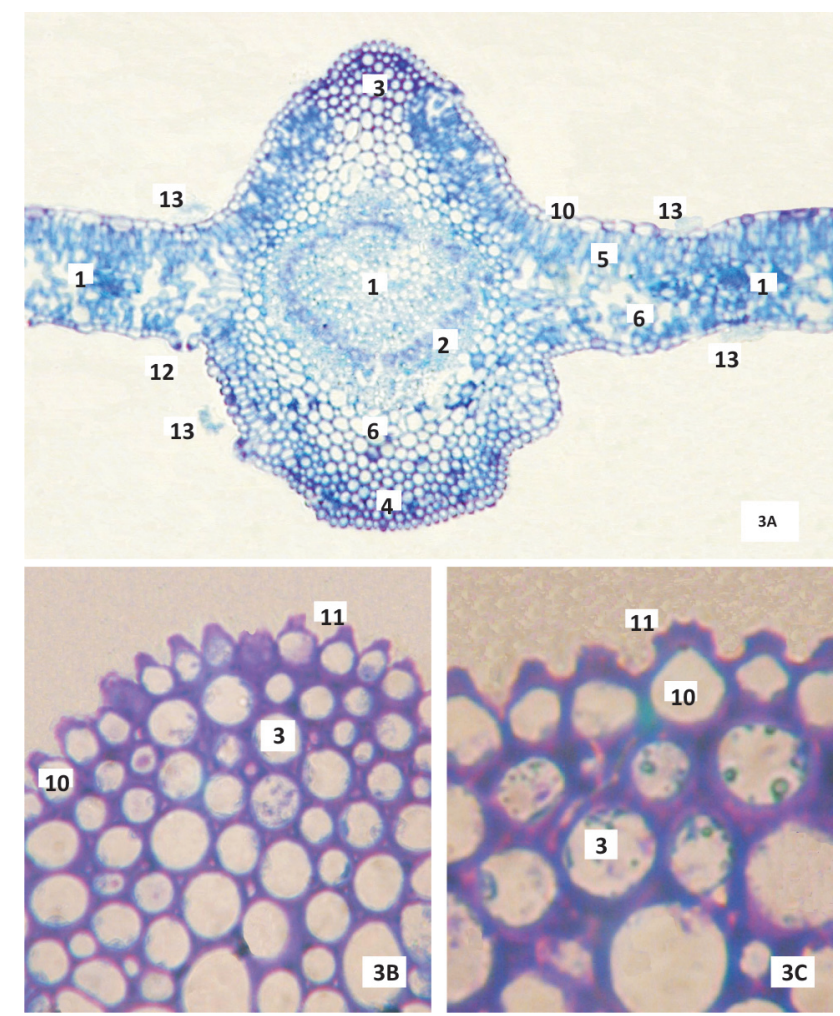

Figura 3 A-C. Seção transversal da lâmina foliar de Dodonaea viscosa Jacq. evidenciando a região da nervura central. Legenda: 1. feixe vascular; 2. esclerênquima; 3 . colênquima anular; 4. colênquima lacunar; 5. parênquima paliçádico; 6. parênquima esponjoso; 10. células epidérmicas; 11. cutícula e formações epicuticulares; 12. estômato; 13. tricoma. Escala: $20 \mu \mathrm{m}$. 


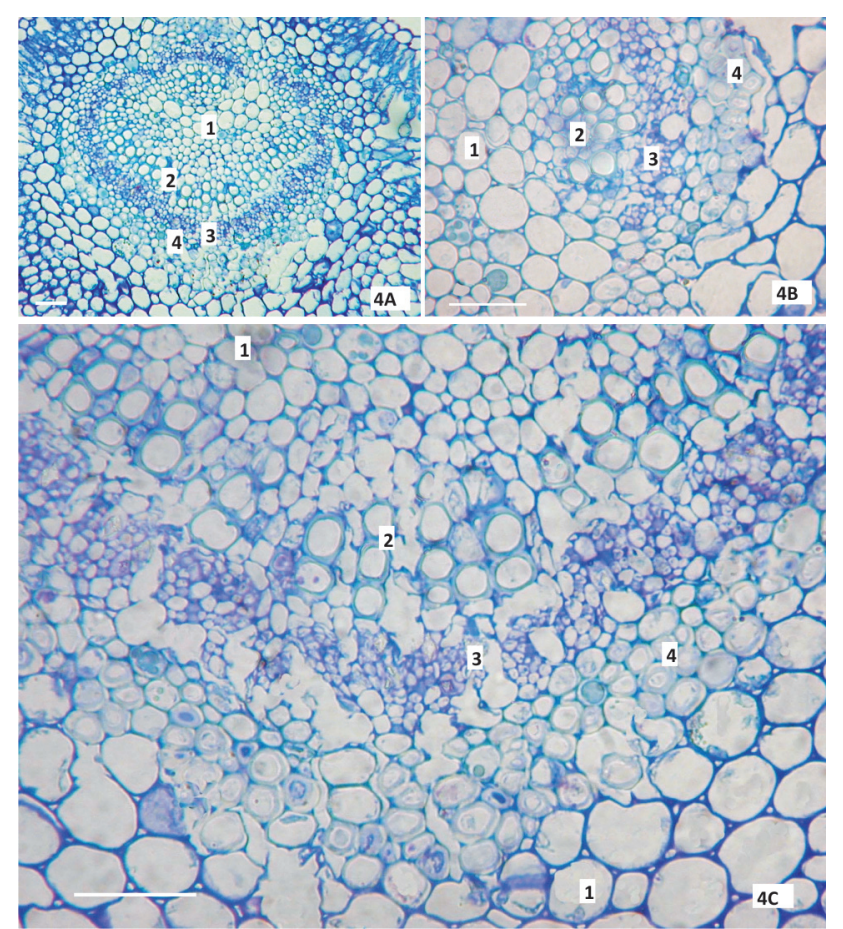

Figura 4 A-C. Seção transversal da região da nervura central da lâmina foliar de Dodonaea viscosa Jacq. Evidenciando a região da nervura central. Legenda: 1. células de parênquima; 2. xilema; 3. floema; 4. esclerênquima. Escala: $20 \mu \mathrm{m}$.

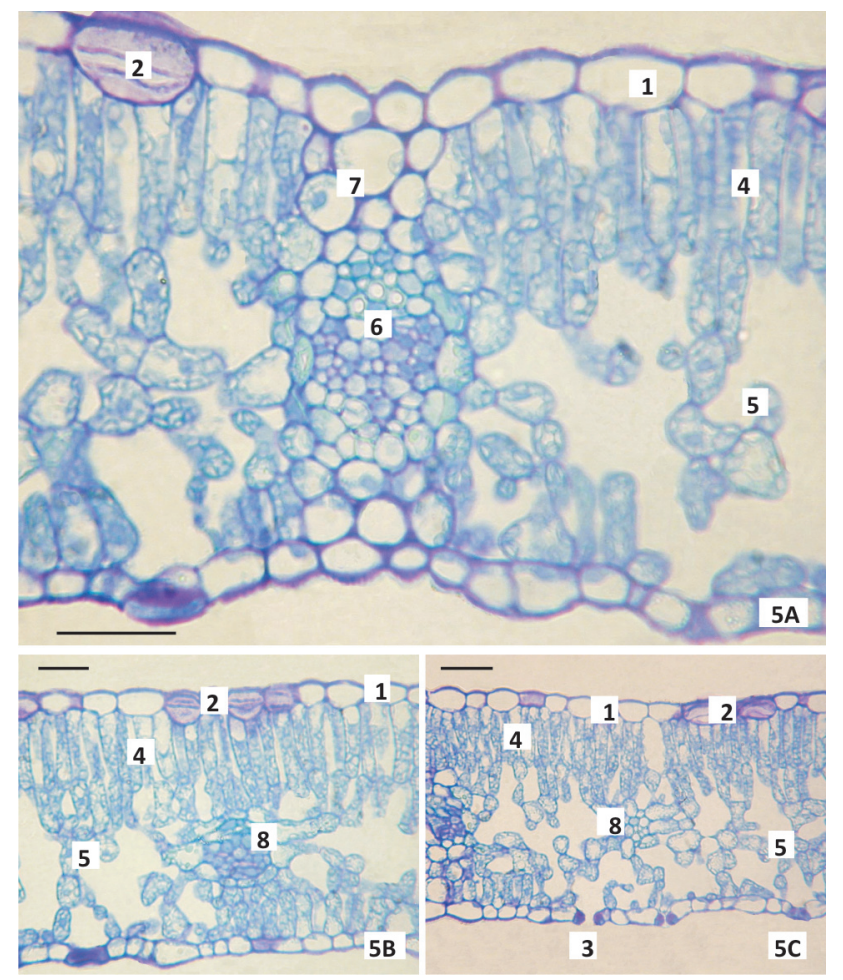

Figura 5 A-C. Seção transversal da lâmina foliar de Dodonaea viscosa Jacq. evidenciando a região lateral. Legenda: 1. células epidérmicas; 2. células de mucilagem; 3 . estômato; 4. parênquima paliçádico; 5. parênquima esponjoso; 6 . feixe vascular de segunda ordem; 7. extensão da bainha vascular; 8 . feixe vascular de menor ordem. Escala: $20 \mu \mathrm{m}$.

\section{CONCLUSÕES}

Os caracteres estruturais das folhas de Dodonaea viscosa Jacq., Sapindaceae, correspondem aos descritos para Sapindaceae, e embora devam ser avaliados em conjunto para ser caracterizado como insumo farmacêutico, alguns aspectos podem ser destacados: $\mathrm{O}$ limbo com forma lanceolada, consistência áspera, venação pinada e o pecíolo triangular com os ângulos arredondados quando em seção transversal. Microscopicamente destaca-se a cutícula com formações lenticulares, os tricomas glandulares e tectores, os estômatos higrofíticos presentes na face abaxial da epiderme, o parênquima paliçádico com até três camadas de células e os feixes vasculares com xilema envolto por floema e cordões de parênquima que ligam um maciço central de parênquima a uma bainha de esclerênquima.

\section{REFERÊNCIAS}

Almeida CE, Manfron MP, Khalil NM, Gamarra AL, Bajerski L, Costa IM, Cocco AO 2001. Contribuição ao estudo fitoquímico e farmacológico de Dodonaea viscosa (L.) Jacquim (Sapindaceae). Saúde 27: 10-14.

Appzzato-da-Glória B, Carmello-Guerreiro SM 2003. Anatomia vegetal. Viçosa: Editora UFV.

Ahmad VU, Fatima I, Fatima A 1987. The sapogenins from Dodonaea viscosa. Fitoterapia 58: 361-362.

Barroso GM 1991. Sistemática de angiospermas do Brasil. Viçosa: Universitária.

Bekker ME, Gerritsen AF 1992. The development of mucilage cells in Hibiscus schizopetalus. Acta Bot Neerl 41: 3142.

CutterEG 1987. Anatomia vegetal. Parte II-Órgãos. Experimentos e interpretações. São Paulo: Rocca.

Costa AF 1982. Farmacognosia. Lisboa: Calouste Gulbenkian.

Cronquist A 1981. An integrated system of classification of flowering plants. New York: Columbia University.

Dickison WC 2000. Integrative Plant Anatomy. San Diego: Harcourt Academic Press.

Esau K 1990. Anatomia das plantas de sementes. São Paulo: Edgar Blücher.

Fahn A 1990. Plant anatomy. Oxford: Pergamon Press.

Fahn A 1986. Structural and functional properties of trichomes of xeromorphic leaves. Ann Bot London 57: 631-637.

Gerrits PO, Smid L 1983. A new, less toxic polimerization system for the embedding of soft tissue in glycol methacrylate and subsequent preparing of serial section. $J$ Microsc 132: 81-85.

Gerlach D 1977. Bothanische mikrotechnik. Stuttgard: GeorgThieme Verlag.

Gurevitch J, Scheiner SM, Fox GA 2002. The ecology of plants. Massachusetts: Sinauer Associates.

Hallahan DL, Gray JC, Callow JA 2000. Advances in botanical research: incorporating advances in plant pathologyPlant trichomes. San Diego: Academic Press.

Hew DV 2001. Comparing uses and collections: The exemple 
of Dodonaea viscosa Jacq. (Sapindaceae). Econ Bot 55: 184-186.

Hickey LJ 1974. Classification de la arquitetura de las hojas de dicotiledoneas. Bol Soc Argent Bot 16: 1-26.

Holmes MG, Keiller DR 2002. Effects of pubescence and waxes on the reflectance of leaves in the ultraviolet and photosynthetic wavebands: a comparison of a range of species. Plant Cell Environ 25: 85-93.

Joly AB 1998. Botânica: Introdução à taxonomia vegetal. São Paulo: Nacional.

Karabourniotis G, Bornman JF, Nikolopoulos D 2000. A Possible optical role of the bundle shearth extensions of the heterobaric leaves of Vitis vinifera and Quercus coccifera. Plant Cell Environ 23: 423-430.

Lorenzi H, Matos RJA 2002. Plantas Medicinais no BrasilNativas e Exóticas. Nova Odessa: Plantarum.

Lorenzi H 1998. Árvores brasileiras-Manual de identificação e cultivo de plantas arbóreas nativas do Brasil. Nova Odessa: Plantarum.

O'Brien TP, McCully ME 1981. The study of plant structure principles and selected methods. Melbourne: Termocarphi Pty. Ltda.

Oliveira F, Lúcia M, Garcia LO 1993. Caracterização farmacognóstica da droga e do extrato fluido de mentrasto-Ageratum conyzoides L. Lecta 11: 63-100.

Oliveira F, Akisue G 1989. Fundamentos de farmacobotânica. São Paulo: Atheneu.

Parkhurst DF 1978. Adaptative significance of stomatal occurrence on one or both surfaces of leaves. $J$ Ecol 66 : 367-383.

Reitz R 1972. Flora Ilustrada Catarinense-Sapindaceae. Itajaí: Herbário Barbosa Rodrigues.

Ricklefs RE 1993. A economia da natureza. Rio de janeiro: Guanabara Koogan.

Rojas A 1992. Screening for antimicrobial activity of crude drug extracts and pure natural products from Mexical medicinal plants. J Ethnopharmacol 35: 275-283.

Ruetze M, Schimit U 1986. Glycol-methacrylat (GMA) als einberttungssystem fúr histologische untersuchungen von koniferen-Nadeln. Eur J Forest Pathol 16: 321-324.

Sachdev K, Kulshreshtha DK 1983. Flavonoids from Dodonaea viscosa. Phytochemistry 22: 1253-1256.

Sajo MG, Rudall PJ 2002. Leaf and stem anatomy of Vochysiaceae in relation to subfamilial systematics. Bot J Linn Soc 138: 339-364.

Schultz A 1985. Introdução à botânica sistemática. Porto Alegre: UFRGS.

Simões CMO 1995. Plantas da Medicina Popular do Rio Grande do Sul. Porto Alegre: UFRGS.

Souza VC, Lorenzi H 2005. Botânica sistemática-guia ilustrado para identificação das famílias de angiospermas da flora brasileira, baseado em APG II. Nova Odessa: Plantarum.

Sobral M, Jarenkow JA 2006. Flora arbórea e arborescente do Rio Grande do Sul. São Carlos: Novo Ambiente.

Stritmatter CGD 1973. Nueva tecnica de diafanización. Bol Soc
Argent Bot 15: 126-129.

Vieira RC, Gomes DMS, Ferraz CLA 1992. Anatomia foliar de Psichotria nuda Wawra e Psychotria leiocarpa Mart. (Rubiaceae). Hoehnea 19: 185-195.

Wagner H, Ludwig C, Grotjahn L, Khan MSY 1987. Biologically active saponins from Dodonaea viscosa. Phytochemistry 26: 697-701.

Wang Yu-Fei, Ferguson DK, Zetter R, Denk T, Garfi G 2001. Leaf architecture and epidermal characters in Zelkova, Ulmanaceae. Bot J Linn Soc 121: 41-57.

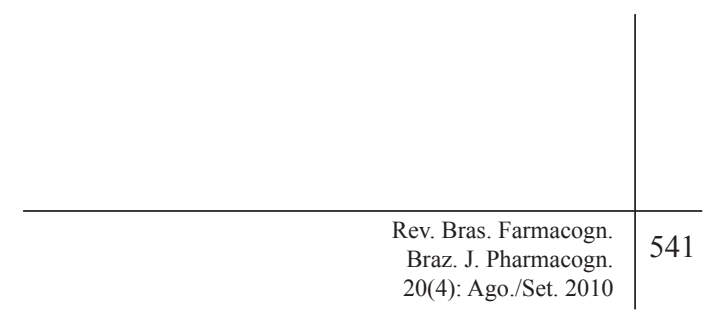

